\title{
KAJIAN SEDIMENTASI DI SUNGAI SAMPEAN BONDOWOSO MENGGUNAKAN PROGRAM HEC-RAS VERSI 4.1
}

\author{
Khafid Iswahyudi ${ }^{1}$, Noor Salim ${ }^{2}$, Taufan Abadi $^{3}$ \\ Program Studi Teknik Sipil, Fakultas Teknik, Universitas Muhammadiyah Jember ${ }^{1,2,3}$ \\ Jl. Karimata 49, Jember 68121, Indonesia \\ email : khafidiswahyudi@gmail.com
}

\begin{abstract}
Sedimentation of the river that is the process of deposition of the material - material that terangkut the flow of river water and can lead to the occurrence of river delta, while sedimentary rock is formed because the process of weathering, erosion, transportation, and deposition (magnification) which occurred in a region of the flow of the river. River Delta which occurs due to the sedimentation process can reduce the amount of water carried by the discharge, so that downstream irrigation needs could not be met due to its full potential is hindered by the buildup of the delta. Characteristics of sedimentation in the lower reaches happened slowly and take place continuously as long as the supply of high sediment loads carried. Predictions of sedimentation that occurs on the river is carried out by taking into account the huge rate of sedimentation based on analytic calculation method, but to ease in portraying the sedimentation that occurs on the river sampean lambreto added Bondowoso done a method of modeling using HEC-RAS application program. HEC-RAS program itself is one of the sediment transport analysis modeling program on the channel as well as the river.
\end{abstract}

Keywords: Analytic Calculation, Sedimentation, HEC-RAS Application Progam, River.

\begin{abstract}
Abstrak
Sedimentasi sungai yaitu proses pengendapan suatu material - material yang terangkut aliran air sungai dan dapat mengakibatkan terjadinya delta sungai, sedangkan sedimen merupakan batuan yang terbentuk karena proses pelapukan, erosi, transportasi, dan deposisi (pengerasan) yang terjadi pada suatu wilayah aliran sungai. Delta sungai yang terjadi karena proses sedimentasi tersebut dapat mengurangi jumlah debit air yang terbawa, sehingga kebutuhan irigasi di daerah hilir tidak bisa terpenuhi secara maksimal karena terhalang oleh penumpukan delta. Karakteristik sedimentasi di hilir terjadi perlahan dan berlangsung menerus selama suplai muatan sedimen yang tinggi terus berlangsung. Prediksi sedimentasi yang terjadi pada sungai dilakukan dengan memperhitungkan besar laju sedimentasi berdasarkan metode perhitungan analitik, namun untuk mempermudah dalam menggambarkan sedimentasi yang terjadi pada sungai sampean Bondowoso dilakukan metode pemodelan menggunakan progam aplikasi HEC-RAS. Progam HEC-RAS sendiri merupakan salah satu progam pemodelan analisis angkutan sedimen pada saluran maupun sungai.
\end{abstract}

Kata kunci: Perhitungan Analitik, Sedimentasi, Progam Aplikasi HEC-RAS, Sungai.

\section{PENDAHULUAN}

\section{Latar Belakang}

Sedimen adalah pecahan pecahan material umumnya terdiri atas uraian batu-batuan secara fisis dan secara kimia. Partikel seperti ini mempunyai ukuran dari yang besar (boulder) sampai yang sangat halus (koloid), dan beragam bentuk dari bulat, lonjong sampai persegi. Hasil sedimen biasanya di peroleh dari pengukuran sedimen terlarut dalam sungai (suspended sediment), dengan kata lain bahwa sedimen merupakan pecahan, mineral atau material organik yang di transforkan dari berbagai sumber dan diendapkan oleh media udara, angin, es atau oleh air dan juga termasuk di dalamnya material yang diendapkan dari material yang melayang dalam air atau dalam bentuk larutan kimia (Asdak, 2007).

Teknologi pemodelan dapat mengkaji pola penyebaran sedimen, pendugaan sumber 
sedimentasi dan dampak yang dihasilkannya baik fisik, kimia maupun biologi. Pola penyebaran sedimen di sepanjang saluran dapat dengan mudah diketahui secara kuantitatif dari waktu ke waktu melalui simulasi model sedimen. Hasil survei sebaran sedimen dapat ditelaah dugaan sumber-sumber potensial sedimen dengan pemodelan menggunakan skenario kondisi awal. Proses fisis, kimia dan biologi dari dampak sedimentasi di saluran dapat diketahui dengan menggunakan skenarioskenario tertentu.Modul model yang digunakan adalah modul Hidrodinamika dan Aliran Sungai untuk mensimulasikan pola sirkulasi arus di muara sungai dan pola aliran sungai dan modul Model Ekosistem digunakan untuk mensimulasikan interaksi antara proses fisis, kimia dan biologi dari dampak sedimentasi terhadap lingkungan.

\section{Identifikasi Masalah}

Sedimen di saluran dapat menimbulkan masalah bagi bangunan diantaranya adalah bangunan irigasi, jembatan, dan pengendali sungai (sofia:1990). Dampak dari sedimentasi yaitu dapat mengurangi kapasitas yang membedakan ialah pada penerapan cara kerja yang lebih mengarah pada analisis sedimentasi, pengaruh sedimen di sepanjang saluran untuk setiap titiknya. Atas dasar uraian diatas. Kajian di sungai sampean Bondowoso menggunakan program HEC-RAS dilakukan guna penanganan sedimentasi saluran yang ada di wilayah sungai sampean dan semoga bisa diterapkan hasilnya untuk waktu mendatang.

\section{Rumusan Masalah}

Dari penjelasan di atas, didapat rumusan masalah sebagai berikut:

1. Berapakah jumlah sedimentasi yang terjadi di sungai sampean Bondowoso?

2. Bagaimana bentuk penampang satu dimensi dari sedimentasi yang terjadi pada sungai sampean Bondowoso?

3. Alternatif apa yang harus dilakukan untuk menanggulangi terjadinya pengendalian sedimentasi di sungai sampean Bondowoso?

\section{Batasan Masalah}

Dalam perencanaan kajian sedimentasi di sungai sampean Bondowoso menggunakan program HEC-RAS, akan dibatasi masalah dalam hal berikut

1. Meninjau sungai sampean Bondowoso sepanjang $5.6 \mathrm{~km}$.

2. Analisa sedimentasi dilakukan menggunakan perhitungan analitik

3. Program HEC-RAS yang digunakan yaitu versi 4.10

\section{Tinjauan Pustaka}

\section{Sedimentasi Sungai}

Sedimentasi merupakan proses pengendapan suatu material - material yang terangkut aliran air sungai dan dapat mengakibatkan terjadinya delta sungai, sedangkan sedimen merupakan batuan yang terbentuk karena proses pelapukan, erosi, transportasi, dan deposisi (pengerasan) yang terjadi pada suatu wilayah aliran sungai. Delta sungai yang terjadi karena proses sedimentasi tersebut dapat mengurangi jumlah debit air yang terbawa, sehingga kebutuhan irigasi di daerah hilir tidak bisa terpenuhi secara maksimal karena terhalang oleh penumpukan delta. Karakteristik sedimentasi di hilir terjadi perlahan dan berlangsung menerus selama suplai muatan sedimen yang tinggi terus berlangsung.

\section{Penentuan Debit Saluran}

Debit saluran adalah volume air yang mengalir per satuan waktu. Data debit merupakan data yang sangat penting sekali perannya, karena merupakan variabel utama untuk menentukan sebuah saluran. Adapun penentuan pemilihan debit dapat dilakukan dengan mengetahui perbandingan luas penampang melintang saluran dengan durasi waktu. Persamaan tersebut bisa dilihat dari rumus debit berikut ini.

Persamaan dasar untuk menentukan debit sungai:

Rumus:

$$
\mathrm{Q}=\mathrm{V} / \mathrm{T}
$$

Dimana:

$$
\begin{aligned}
& \mathrm{Q}=\text { Debit sungai } \mathrm{m}^{3} / \mathrm{dt} \\
& \mathrm{V}=\operatorname{Volume}(\mathrm{m} / \mathrm{dt}) \\
& \mathrm{T}=\operatorname{Waktu}\left(\mathrm{m}^{2}\right)
\end{aligned}
$$


Perhitungan Kecepatan pada Saluran Terbuka:

Untuk perhitungan kecepatan pada saluran terbuka dapat menggunakan rumus manning. Parameter yang dijadikan acuan antara lain adalah jari - jari hidrolis, kemiringan dasar saluran dan koefisien manning yang dapat dilihat dari tabel 2.1 berikut ini. Untuk persamaanya bisa dilihat dari rumus 2.2 berikut ini,

Rumus:

$$
\text { MANNING } V=\frac{1}{\mathrm{n}} R^{2 / 3} \cdot 1^{1 / 2}
$$

Dimana:

$\mathrm{V}=$ kecepatan aliran $(\mathrm{m} / \mathrm{s})$

$\mathrm{R}=$ jari-jari hidrolis $(\mathrm{m})$

$i=$ kemiringan dasar saluran

$n=$ koefisien manning

\section{Kerangka Konsep Penelitian Dan Hipotesis}

\section{Kerangka Konsep Penelitian}

Berdasarkan rumusan masalah dan tujuan penelitian yang telah dijelaskan diatas, maka didapat konsep penelitian sebagai berikut :

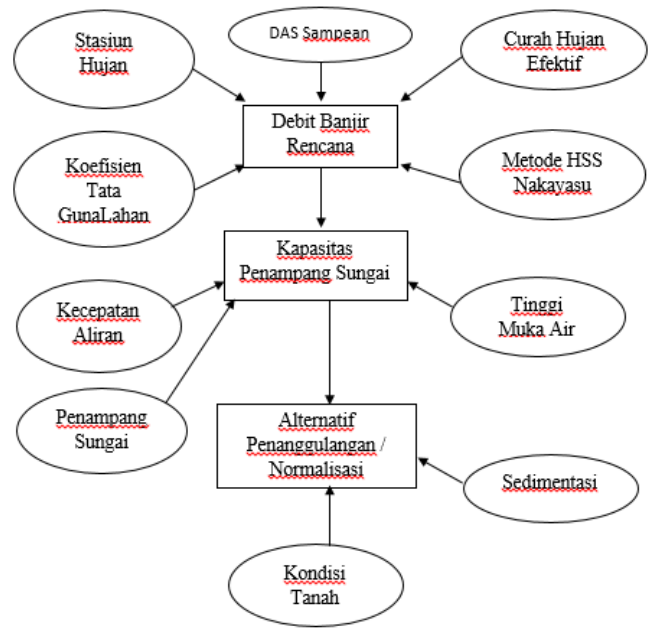

Gambar 1. Kerangka Konsep Penelitian

\section{Hipotesis}

Berdasarkan rumusan masalah, tujuan penelitian serta kerangka konsep penelitian yang telah dijelaskan diatas,maka dapat di kemukakan hipotesis sebagai berikut:

1. Jumlah sedimentasi yang terjadi di sungai sampean Bondowoso.

2. Bentuk penampang satu dimensi dari sedimentasi yang terjadi pada sungai sampean Bondowoso.
3. Solusi penanggulangan lebih efektif dengan cara normalisasi sedimentasi.

\section{Lokasi Penelitian}

Lokasi penelitian di sungai sampean di

Kabupaten Bondowoso.

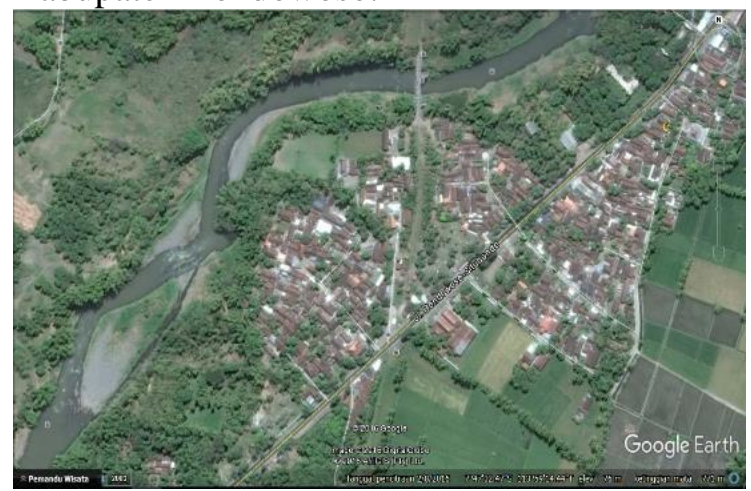

Gambar 2. Lokasi Penelitian

\section{METODE PENELITIAN}

\section{Lokasi Studi}

Bondowoso adalah sebuah kota yang berada di Provinsi Jawa Timur yang dilewati oleh aliran sungai. Sungai induk yang melewati Bondowoso adalah sungai sampean. Daerah rawan banjir mencakup 33,33\% wilayah Kabupaten Bondowoso, khususnya kawasankawasan yang berada di sepanjang aliran sungai sampean. Sungai ini berada pada koordinat $8^{\circ} 03$ '20.62" S 1134'43.41 E sampai dengan koordinat 746'41.70” S 113059'29.39 E. Berikut peta aliran sungai sampean.

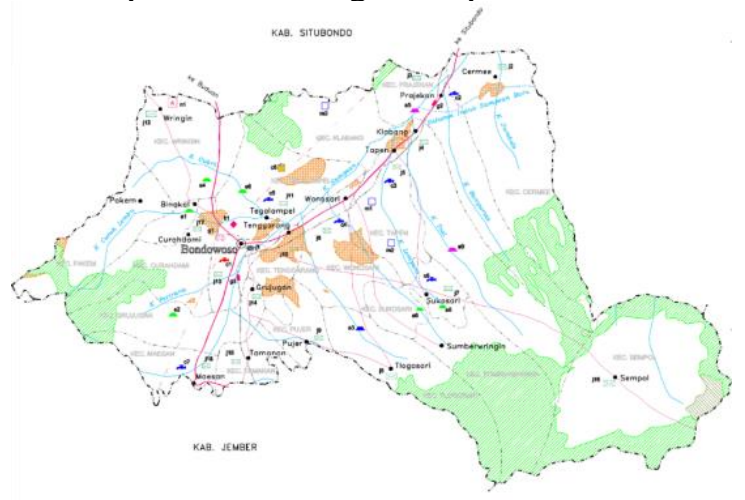

Gambar 3 Peta Aliran Sungai Sampean Sumber: Dinas Pengairan Bondowoso

Lokasi yang diteliti adalah sungai sampean Bondowoso seperti yang terlihat pada Gambar 4. 


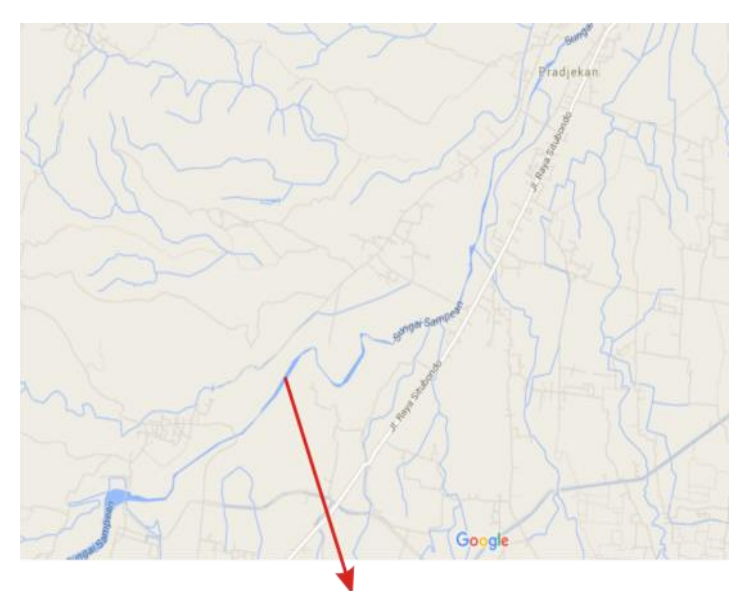

Gambar 4. Lokasi Sungai Sampean

Sumber: Google Map

\section{Langkah-langkah Penelitian}

Dalam melakukan kajian sedimentasi di sungai sampean ini, ada beberapa langkahlangkah yang harus dilakukan antara lain.

Pengumpulan Data

Data primer merupakan data yang didapat berdasarkan pengamatan lapangan. Data primer yang didapat merupakan data hasil observasi dan data pengamatan yang dilakukan di lokasi penelitian. Data yang diambil antara lain,

1. Pengambilan sedimen

Pengambilan sedimen dilakukan dengan menggunakan metode Equal Widht Increment (EWI) yaitu metode dengan cara membagi lebar penampang sungai menjadi beberapa bagian yang sama tergantung dari jumlah sampel yang akan di ambil. Vertical pengambilan sampel terletak pada tengah - tengah dari bagian penampang tempat pengambilan sampel.

2. Data sedimentasi saluran dengan menggunakan uji analisa saringan. Pelaksanaan uji analisis saringan dilakukan di laboratorium mekanika tanah Fakultas Teknik Universitas Muhammadiyah Jember. Alat yang digunakan dalam uji analisis saringan adalah sebagai berikut ;

a. Oven yang dilengkapi dengan pengatur suhu untuk memanasi $110^{\circ}$ C

b. Satu set saringan dengan beberapa diameter ukuran c. Timbangan dengan ketelitian $0,2 \%$ dari berat benda uji

d. Mesin pengguncang saringan Adapun tahapan dalam analisis saringan adalah sebagai berikut :

a. Benda uji dikeringkan dengan oven pada suhu $110^{\circ} \mathrm{C}$

b. Saringan disusun dengan ukuran diameter yang besar diatas

c. Sampel benda uji dimasukkan ke dalam saringan dan diayak selama 15 menit.

Setelah dilakukan uji analisis saringan, maka ditampilkan dalam tabel 3.1 dengan rincian sebagai berikut:

a. Jumlah berat tertahan untuk masing masing ukuran saringan

b. Jumlah prosentase berat benda uji tertahan terhadap berat total secara komulatif

c. Jumlah prosentase berat benda uji yang melalui masing - masing saringan

d. Grafik anlisis saringan berdasarkan diameter butiran dan komulatif prosentase lolos saringan

Tabel 1. Tabel ukuran ayakan/saringan dalam perhitungan analisa saringan

\begin{tabular}{|c|c|c|}
\hline No & Nomer ayakan & $\begin{array}{c}\text { Diameter lubang } \\
\text { (mm) }\end{array}$ \\
\hline 1 & $3 / 4$ & 19,5 \\
\hline 2 & $3 / 8$ & 9,5 \\
\hline 3 & 4 & 4,76 \\
\hline 4 & 10 & 2 \\
\hline 5 & 20 & 0,85 \\
\hline 6 & 40 & 0,3681 \\
\hline 7 & 60 & 0,25 \\
\hline 8 & 100 & 0,15 \\
\hline 9 & 140 & 0,10 \\
\hline 10 & 200 & 0,075 \\
\hline 11 & Pan & \\
\hline
\end{tabular}

Sumber: (ASTM C-136-46) 


\section{Flowchart Pelaksanaan Penelitian}

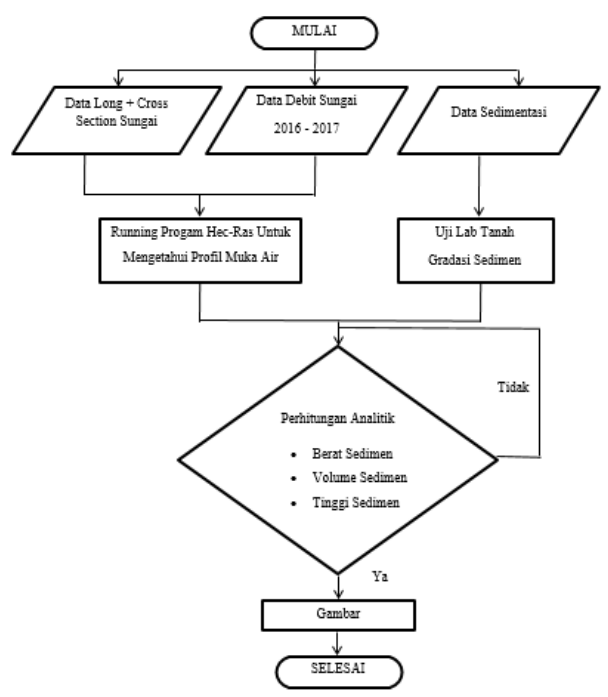

\section{HASIL DAN PEMBAHASAN}

1. Kondisi Saluran Sungai Sampean

\section{Bondowoso}

Sungai Sampean merupakan sungai yang melewati kota Bondowoso. Sungai tersebut berada dibawah pengawasan UPT. PSDA Bondowoso. Panjang sungai sampean dari hulu sampai muara $\pm 67 \mathrm{Km}$. Pada pembahasan kali ini, penulis akan menganalisa kapasitas penampang sungai dari titik DAM Sampean Baru hingga DAM Sampean Lama yang berada di wilayah Situbondo. Karena pada sepanjang jalur tersebut merupakan daerah rawan banjir. Jarak antara DAM Sampean baru ke DAM Sampean lama sekitar 5.6 Km.

\section{Running Program Hec-Ras}

Input Data

Buka aplikasi progam Hec-Ras. Pilih File New Project. Masukkan nama project

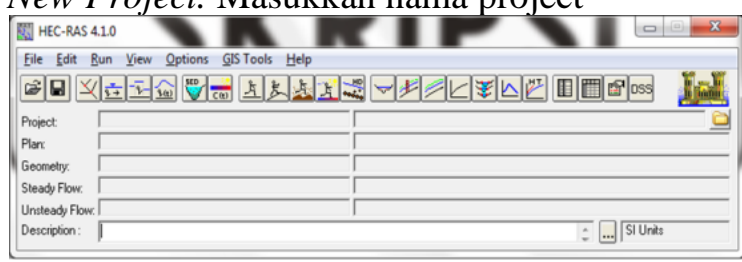

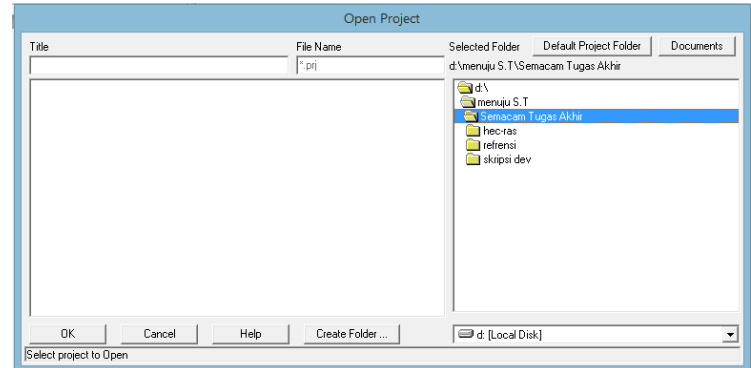

Gambar 5. Tampilan Program Aplikasi HEC RAS

Gambar 6. Tampilan Input New Projectz

1. Pilih Options $\rightarrow$ Unit System. Pilih sistem internasional untuk membuat data dalam satuan SI (Standart Indonesia).

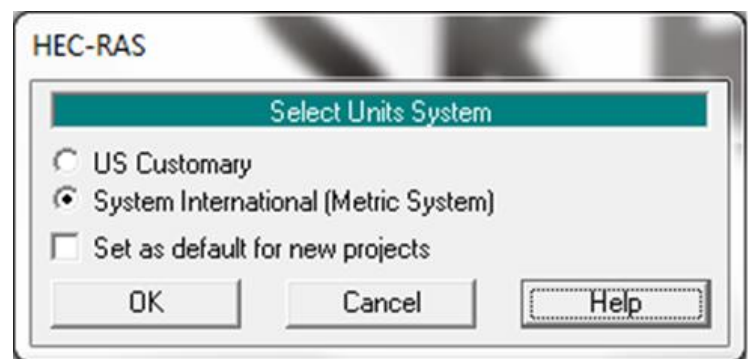

Gambar 7. Tampilan Unit System

2. Kemudian pilih Edit / Enter Geometric Data. Kemudian gambar sketsa sungai yang di tinjau dengan cara Klik tombol River Reach. Pada layar yang muncul, isikan nama sungai dan nama reach.

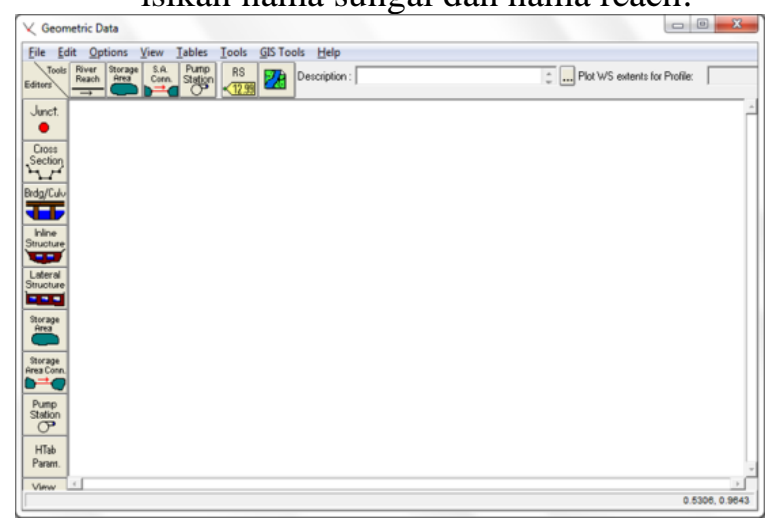

Gambar 8. Tampilan Geometric Data 


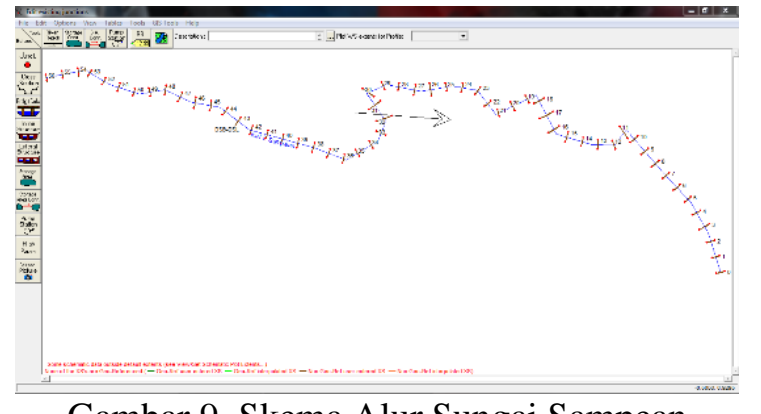

Gambar 9. Skema Alur Sungai Sampean

\section{Perhitungan Analitik Sedimentasi}

Angkutan sedimen total pada tugas akhir ini dihitung menggunakan persamaan Laursen, rumus ini dipilih karena data dari variabel yang dibutuhkan tersedia dan ukuran diameter sedimen sesuai dengan persamaan ini dimana untuk ukuran partikel jenis pasir hingga lanau. Konsentrasi sedimen dengan metode Laursen dihitung dengan persamaan berikut:

Dengan :

$$
C_{t}=0,01 \gamma\left(\frac{d_{50}}{D}\right)^{7 / 6}\left(\frac{\tau^{\prime}}{\tau c i}\right) f\left(\frac{U_{*}}{\omega_{I}}\right)
$$

$$
\begin{aligned}
& C_{t}=\text { jumlah sedimen }\left(\mathrm{kg} / \mathrm{m}^{3}\right) \\
& \gamma=\text { berat jenis air }\left(\mathrm{kg} / \mathrm{m}^{3}\right) \\
& d_{50}=\text { ukuran partikel sedimen } \\
& \text { berpresentase } 50 \%(\mathrm{~mm}) \\
& \mathrm{D}=\text { kedalaman rata-rata }(\mathrm{m}) \\
& \tau^{\prime}=\text { tegangan geser }\left(\mathrm{N} / \mathrm{m}^{2}\right) \\
& \tau \mathrm{ci}=\text { tegangan geser } \mathrm{kritis}\left(\mathrm{N} / \mathrm{m}^{2}\right) \\
& U_{*}=\text { kecepatan geser }(\mathrm{m} / \text { detik }) \\
& \omega_{I}=\text { kecepatan jatuh partikel sedimen } \\
& \text { ukuran I }(\mathrm{m} / \text { detik })
\end{aligned}
$$

Tabel 2. Data Saluran di Setiap STA

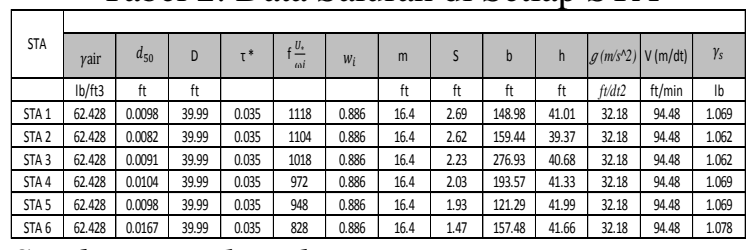

Sumber: Hasil Perhitungan

Tabel 3. Perhitungan Ketebalan Sedimen

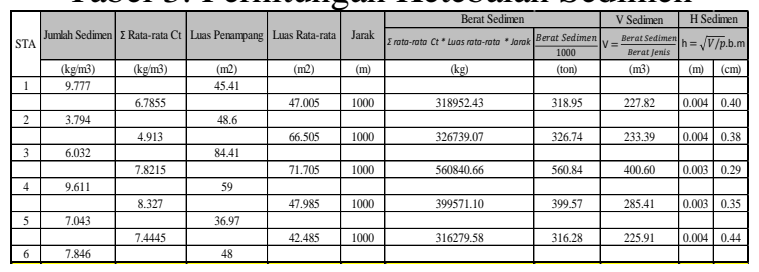

Sumber: Hasil Perhitungan
Dari tabel diatas, terdapat jumlah sedimen STA $1=9.777 \mathrm{~kg} / \mathrm{m} 3$, STA $2=3.794 \mathrm{~kg} / \mathrm{m} 3$, STA $3=6.032 \mathrm{~kg} / \mathrm{m} 3$, STA $4=9.611 \mathrm{~kg} / \mathrm{m} 3$, STA $5=7.043 \mathrm{~kg} / \mathrm{m} 3$, STA $6=7.846 \mathrm{~kg} / \mathrm{m} 3$ dengan rata-rata STA $1-S T A 2=6.7855 \mathrm{~kg} / \mathrm{m} 3$, STA 2-STA $3=4.913 \mathrm{~kg} / \mathrm{m} 3$, STA 3-STA $4=$ $7.8215 \mathrm{~kg} / \mathrm{m} 3$, STA 4-STA $5=8.327 \mathrm{~kg} / \mathrm{m} 3$, STA 5-STA $6=7.4445 \mathrm{~kg} / \mathrm{m} 3$ dan luas penampang STA $1=45.41 \mathrm{~m} 2$, STA $2=48.6$ $\mathrm{m} 2$, STA $3=84.41 \mathrm{~m} 2$, STA $4=59 \mathrm{~m} 2$, STA 5 $=36.97 \mathrm{~m} 2$, STA $6=48 \mathrm{~m} 2$ dengan rata-rata STA 1-STA $2=47.005 \mathrm{~m} 2$, STA 2-STA $3=$ $66.505 \mathrm{~m} 2$, STA 3 -STA $4=71.705 \mathrm{~m} 2$, STA 4 STA $5=47.985 \mathrm{~m} 2$, STA 5 -STA $6=42.485$ $\mathrm{m} 2$ dan jarak tiap STA $1000 \mathrm{~m}$. Dari data tersebut maka akan mengetahui hasil berat sedimen, volume sedimen dan tinggi sedimen tiap STA seperti pada tabel 3 untuk mendapatkan angka ketebalan sedimen dihitung dengan menggunakan rumus sebagai berikut:

Dengan:

$$
\mathrm{H}=\sqrt{ }\left(\frac{V}{\text { p.b.m }}\right)
$$

$$
\begin{aligned}
& \mathrm{H}=\text { tinggi sedimen }(\mathrm{m}) \\
& \mathrm{V}=\operatorname{volume} \text { sedimen }\left(\mathrm{m}^{3}\right) \\
& \mathrm{p}=\text { jarak tiap STA }(\mathrm{m}) \\
& \mathrm{b}=\text { lebar penampang basah }(\mathrm{m}) \\
& \mathrm{m}=\text { kemiringan tebing }(\mathrm{m})
\end{aligned}
$$

\section{KESIMPULAN DAN SARAN}

\section{Kesimpulan}

Berdasarkan hasil dan pembahasan yang telah dilakukan dalam kajian ini maka dapat disimpulkan beberapa hal sebagai berikut :

1. Dari hasil perhitungan sedimentasi, jumlah sedimentasi STA $1=9.777 \mathrm{~kg} / \mathrm{m}^{3}$, STA 2 $=3.794 \mathrm{~kg} / \mathrm{m}^{3}$, STA $3=6.032 \mathrm{~kg} / \mathrm{m}^{3}$, STA $4=9.611 \mathrm{~kg} / \mathrm{m}^{3}$, STA $5=7.043 \mathrm{~kg} / \mathrm{m}^{3}$, STA $6=7.846 \mathrm{~kg} / \mathrm{m}^{3}$. Dengan tinggi sedimen tiap STA $0.40 \mathrm{~cm}, 0.38 \mathrm{~cm}, 0.29$ $\mathrm{cm}, 0.35 \mathrm{~cm}$ dan $0.44 \mathrm{~cm}$.

2. Running progam aplikasi HEC-RAS untuk mengetahui penampang melintang dan profil muka air dari data long+cross section dan debit, dan hasil uji saringan sedimen di laboratorium tanah diketahui bahwa sedimen di sungai sampean Bondowoso tergolong fine sand atau pasir halus.

3. Alternatif solusi untuk menanggulangi terjadinya pengulangan sedimentasi Sungai 
Sampean adalah dengan cara normalisasi. Yaitu dengan total volume sedimen $1373.13 \mathrm{~m}^{3}$ bisa di normalisasikan di setiap STA dengan menggunakan 6 excavator CAT6090 dengan bucket kapasitas 52.0 $\mathrm{m}^{3} / \mathrm{jam}$.

\section{Saran}

Berdasarkan pada Tugas Akhir " Kajian Sedimentasi Di Sungai Sampean Bondowoso dengan Menggunakan Program HEC-RAS versi 4.1" ini, penyusun ingin memberikan beberapa saran terkait dengan masalah tersebut.

1. Memperhitungkan sedimen yang terdapat di dalam Sungai Sampean Bondowoso dan melakukan pengecekan kondisi tanah di sekitar Sungai Sampean.

2. Perlu dilakukan pemeliharaan Sungai secara rutin agar sungai menjadi tampak lebih bersih dan sungai dapat berfungsi secara optimal.

3. Pada penggunaan progam HEC-RAS untuk analisa sungai, sebaiknya tersedia datadata yang lengkap untuk input yaitu data geometri seperti cross section, skema alur sungai, kondisi alur sungai dan data lainya.

\section{DAFTAR PUSTAKA}

Irawan, Erik Setyo, 2014. Analisis Pemodelan Sedimentasi Di Saluran Kencong Timur (Bedodo) Menggunakan Progam HECRAS. Jember.

Istiarto, 2014. Simulasi Aliran 1 Dimensi dengan HEC-RAS. Yogyakarta.

Jurnal Teknik ITS, 2017 Laju Sedimentasi Pada Tampungan Bendungan Tugu Trenggalek.

Kusumo, Agung Tejo, 2016. Tugas Akhir Analisa dan Evaluasi Kapasitas Penampang Sungai Sampean Bondowoso Dengan menggunakan Program HECRAS 4.1. Jember.

Rizal, NS. 2014. Aplikasi Perencanaan Irigasi dan Bangunan Air. Jember

Soemarto, CD. 1995. Hidrologi Teknik. Jakarta: Erlangga. 